\title{
Female Clients Satisfaction towards Primary and Secondary Eye Health Facilities and Cost of Eye Care in Nepal
}

\author{
Radhika Upreti Oli ${ }^{1}$, Manish Poudel ${ }^{1}$, Yadira Perez Hazel ${ }^{2}$, Anu Manandhar ${ }^{1}$, \\ Mohan Krishna Shrestha ${ }^{1}$, Reeta Gurung ${ }^{1}$ \\ 'Tilganga Institute of Ophthalmology, Nepal Eye Program, Nepal \\ ${ }^{2}$ The Fred Hollows Foundation, Darwin, Australia
}

\begin{abstract}
Introduction: In Nepal, females suffer from disproportionately higher burden of blindness and vision impairment with low access to eye care. The available knowledge is inadequate to address the issues related to gender and generate information to reduce the gender disparity. The aim of this study was to determine female clients' satisfaction with services at eye facilities in Nepal and to estimate the cost of cataract surgery.
\end{abstract}

Materials and methods: Exit interviews were conducted in 2018 with 308 female clients from eight facilities in five districts. Face to face interviews were conducted using a pretested semi-structured questionnaire adopted from the midterm review of Vision 2020.

Results: The mean age of participants was $54 \pm 17$ years. Ninety seven percent $(97 \%)$ of the participants reported that they received service as per their expectation and were satisfied with the service of the facilities. Major factors for satisfaction were: thorough eye examination (54\%), behavior of health staff (40\%), and cleanliness of health facility (39\%). Another eighty percent (80\%) of the participants mentioned that they would recommend or return to the same facility. Fifteen percent of the participants perceived that they faced problems at the eye facility because of their gender. Around three quarters $(73 \%)$ paid health expenses from their pocket. Most (83\%) of the participants rated user fees as either reasonable or inexpensive.

Conclusion: The majority of participants reported receiving service as expected and willingness to return to the same eye health facility for future consultation. However, most participants had to pay the health care expenses out-of-pocket.

Key words: Eye, Female, Satisfaction.

Financial Interest : Australia NGO Cooperation Program (ANCP), The Fred Hollows Foundation

Conflict of Interest: Nil

Received : :27.08.2020

Accepted : 20.03.2021

Corresponding Author

Mrs Radhika Upreti Oli

Senior research officer

Tilganga Institute of Ophthalmology,

Nepal Eye Program, Nepal

E-mail: radhika.upreti@tilganga.org, up.radhikaa@gmail.com

Contact:+9779849988888
Access this article online

Website: www.nepjol.info/index.php/NEPJOPH

DOI: https://doi.org/10.3126/nepjoph.v13i2.30839

Copyright (C) 2021 Nepal Ophthalmic Society

ISSN: 2072-6805, E-ISSN: 2091-0320

This work is licensed under a Creative Commons

Attribution-NonCommercial-NoDerivatives 4.0 International License (CC BY-NC-ND). 


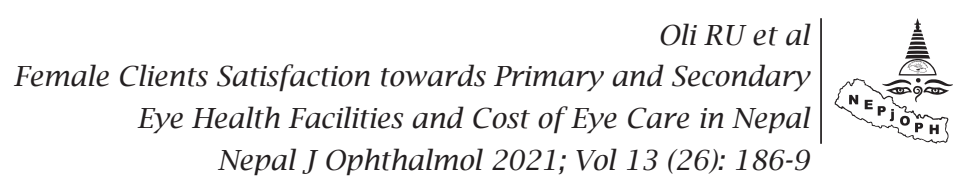

\section{INTRODUCTION}

Women carry nearly two-third of the burden of blindness in the world(Abou-Gareeb et al, 2001)with a low rate of utilization of eye services (Lewallen et al, 2009). In Nepal, gender disparity in eye health is found to be persistent, profound and pervasive(Upadhyay, 2010; Sapkota, 2012). Women are found to be more satisfied when they are treated with respect, courtesy and dignity(Senarath, Fernando and Rodrigo, 2006). The major barriers of low service utilization by females are lack of gender responsive care and cost of service(Tilganga Institute of Ophthalmology, 2017). In Nepal, there is limited knowledge on the satisfaction of female patients attending eye care facilities and the cost of eye care service. Thus, this research aimed to study female clients' satisfaction with overall services at select eye facilities in Nepal and to provide an estimate of the direct and indirect cost of cataract surgery.

\section{MATERIALS AND METHODS}

We conducted this study as a baseline survey of Effectiveness of eye health care package to increase access to eye health care for women: A pragmatic trial in selected districts of Nepal'. It received approval from Nepal Health Research Council (Reg. no.376/2018). We conducted this study across eight different eye health facilities in Central and Western Nepal. These sites were the implementing partners of the Regional Eye Care Project of Tilganga Institute of Ophthalmology and The Fred Hollows
Foundation. We calculated the sample size as 298 based on previous literature (Sunaulo Parivar Nepal/ Marie Stopes International Nepal, 2013) at 5\% level of precision. We conducted face to face interviews using a pretested semi structured questionnaire adopted from the Mid-term Review of Vision 2020. Each participant gave written informed consent to be a part of this study.

\section{RESULTS}

\section{Satisfaction towards eye care services}

We interviewed a total of 308 female eye service users. The mean age of the participants was $57 \pm 16$ years, $71 \%$ were illiterate and $8 \%$ were involved in paid income. Participants had to spend 60 minutes (range: 5 to 620 minutes) to arrive at the facility. A plurality (43\%) of the participants noted that they made the choice to attend a particular eye health facility.

Ninety-seven percent reported that they received services as per their expectation and were satisfied with the overall service. Similarly, 76\% had to wait for less than an hour before receiving eye care. The most commonly reported problem faced were long waiting times, difficulty finding examination rooms, no separate queue and unisex toilets. Another 15\% perceived that they faced these problems because of being female.

A large majority of the participants visiting for more than one time mentioned that the service (100\%), service providers (99\%) and medicine/ glass $(81 \%)$ were regularly available in the center. 
More than $90 \%$ of those instructed for cataract surgery, noted that they were willing to get cataract surgery at the same center. Similarly, more than $80 \%$ of the first time visitors replied that they would come back for future consultation. The positive factors for returning to the same center if needed were: thorough examination (54\%), behavior of health staff (40\%), cleanliness of facility (39\%), overall cost and transportation facility (37\%), orderly procedure (22\%) and availability of female staff (21\%). Likewise, the weakness of the facility as stated by those who would not like to revisit the facility were: staff were not listening to problems (22\%), queue was not followed (11\%), did not examine thoroughly (11\%).

\section{Cost of cataract surgery}

In this study, $19 \%$ of the participants reported having received cataract surgery in recent visits. Wide variation was observed across direct and indirect expenses at the study centers. On average, the patient had to pay around NRs 2030 to get a cataract surgery. This figure ranges from NRs 20 for a patient who gets a full subsidy to around NRs 12,000 for a patient who had to pay on their own. Around three quarters (73\%) of the respondents covered the expenses from their own pocket. Most of the participants rated the user fee as reasonable at the eye center.

\section{DISCUSSION AND CONCLUSION}

In this study, participants travelled nearly 60 minutes to arrive at the eye health facility. In comparison to the location of general and reproductive health centers, the eye health facilities are situated at a farther distance. This finding can be used as a basis for integrating eye care in general health care services in Nepal.

In our study, $97 \%$ of the participants mentioned that they received the service as expected and were satisfied with the overall services. This finding is higher than other studies (Gurung et al, 2006; Rizyal, 2012). This could be due to differences in study setting and changes observed over recent years. The most commonly reported problems at the eye health facility in our study were similar to the other studies (Gurung et al, 2006; Rizyal, 2012). Similarly, in this study around $15 \%$ of the participants perceived that they faced problems because of their female gender.

A proxy measure of satisfaction was assessed by asking the participants if they were willing to return to the study eye facility for future consultation. A large majority of them $(80 \%)$ mentioned that they would like to return to the same eye facility. Patient satisfaction ranges from $74 \%$ to $76 \%$ across different eye facilities in Nepal (Gurung et al, 2006; Rizyal, 2012).

Most of the participants (73\%) paid from out of pocket for cataract surgery. This figure was even higher than the out of pocket expenditure for health in Nepal which was around 60\% (World Health Organisation South East Asia, 2017). Also, more than $80 \%$ of the participants mentioned that the user fee was affordable to 
them. The cost of cataract surgery was as high as NRs 12,000 which is much higher than the per capita GDP (per month) of an average Nepali.

We conducted this study in eye facilities where other existing projects were being implemented which might have affected the findings. It is included only among female patients, thus comparison with male patients is not possible.

\section{REFERENCES}

Abou-Gareeb, I. et al. (2001) 'Gender and blindness: a meta-analysis of population based prevalence surveys (Abstract Citation)’, Ophthalmic Epidemilogy, 8(1), pp. 39-56. doi: 10.1076/opep.8.1.39.1540; PMid:11262681

Gurung, K. et al. (2006) 'Patients perception towards the eye health care system in a tertiary eye care centre in Nepal', Nepal Medical College Journal, 8(2), pp. 115-117. Available at: https://europepmc.org/article/med/17017402

Lewallen, S. et al. (2009) 'Cataract surgical coverage remains lower in women', British Journal of Ophthalmology, 93(3), pp. 295-298. doi: 10.1136/bjo.2008.140301; PMid:19091848

Rizyal, A. (2012) 'Patients ' satisfaction with eye care services at Nepal Medical College', Nepal Medical College Journal, 14(3), pp. 172-175. PMid: 24047009

Sapkota, Y. (2012) Epidemiology of Blindness in Nepal. Kathmandu.Available at: https://www.researchgate.net/ publication/236308859_Epidemiology_of_Blindness_in_Nepal_2012

Senarath, U., Fernando, D. N. and Rodrigo, I. (2006) 'Factors determining client satisfaction with hospital-based perinatal care in Sri Lanka', Tropical Medicine \& International Health, 11(9), pp. 1442-51. doi: 10.1111/j.13653156.2006.01698.x; PMid:16930267

Sunaulo Parivar Nepal/ Marie Stopes International Nepal (2013) 'SPN/MSI Nepal 2013 Client Exit Interview Report Assessing client satisfaction \& perception of quality with services received from Marie Stopes Centres (Abstract Citation)', Journal of Nepal Health Research Council. Available at: http://library.nhrc.gov.np:8080/nhrc/bitstream/ handle/123456789/754/SPN.docx?sequence=1

Tilganga Institute of Ophthalmology (2017) Gender Analysis of Eye Health in Nepal. Nepal.

Upadhyay, M. P. (2010) 'Rethinking eye care : from exclusion to equity', Nepalese Journal of Ophthalmology, 2(3), pp. 1-2. doi: 10.3126/nepjoph.v2i1.3696; PMid:21141319

World Health Organisation South East Asia (2017) Health financing profile 2017 Nepal. Available at: https://apps. who.int/iris/handle/10665/259643 